\title{
Cracking and Failure Characteristics of Flame Cut Thick Steel Plates
}

\author{
T. JOKIAHO (1), S. SANTA-AHO (1), P. PEURA (1), and M. VIPPOLA (1)
}

The manufacturing of thick wear-resistant steel plates commonly leads to a layered structure and non-uniform properties in the thickness direction which makes the processing and utilization of the plates problematic. The processing steps of thick plates include flame cutting, which generates a heat-affected zone and high residual stresses into the cut edge. In the worst case, the cutting causes cracking. However, the residual stress level alone is not high enough to break a wear-resistant steel plate that behaves normally. Therefore, high-tensile stress also requires a microstructurally weak factor for crack initiation. For this reason, the main objective of this study is to reveal the main microstructural reasons behind the cracking of plates in flame cutting. To achieve this, plate samples containing cracks are mechanically tested and analyzed by electron microscopy. The results show that cracks are commonly formed horizontally into the tempered region of the heat-affected zone. Cracks initiate in the segregations, which typically have a higher amount of impurity and alloying elements. Increased impurity and alloying content in the segregations decreases the cohesion of the prior austenite grain boundaries. These weakened grain boundaries combined with high-residual tensile stress generate the cracks in the flame-cutting process.

https://doi.org/10.1007/s11661-020-05639-x

(C) The Author(s) 2020

\section{INTRODUCTION}

THE fabrication and solidification processes of thick wear-resistant steel plates are complex. In thick plates, cooling can occur unevenly and the solidification in continuous casting can be at different stages at different depths of the plate. This leads to the partition of solutes between liquid and solid phases because the solubility of the solutes is higher in the liquid phase than in the solid phase. As a consequence, the solid phase rejects the excess solutes at the solid-liquid interface and they are transferred into the coexisting liquid phase. This creates an enrichment of solutes in the remaining liquid during solidification and the last solidified regions have a significantly higher solute content compared to the nominal composition of the steel. ${ }^{[1,2]}$ These solute-enriched regions, known as segregations, are then pressed during rolling into the form of a thin sheet or strip, thus causing a layered structure in the thick plate. Segregations are typically formed in the center region of the plate and it has been found ${ }^{[1]}$ that they contain

T. JOKIAHO, S. SANTA-AHO, P. PEURA, and M. VIPPOLA are with the Materials Science and Environmental Engineering, Faculty of Engineering and Natural Sciences, Tampere University, P.O. Box 589, 33014 Tampere, Finland. Contact e-mail: tuomas.jokiaho@tuni.fi

Manuscript submitted 14 August, 2019.

Article published online January 30, 2020 significantly higher amounts of carbon, phosphorus, and manganese compared to the nominal composition of the steel. Another study showed [3] that center segregations have elevated concentrations of carbon (C), silicon ( $\mathrm{Si})$, manganese $(\mathrm{Mn})$, chromium $(\mathrm{Cr})$, nickel (Ni), and molybdenum (Mo). Both studies showed that, relatively, carbon had the highest increase in segregations and it was shown that the amount and severity of the segregation depended on the manufacturing parameters of the plates. ${ }^{[1,3]}$

Due to the segregations and layered structure, the mechanical properties of thick plates can be significantly different, depending on the location in the thickness direction; commonly, the properties deteriorate towards the center. ${ }^{[2,4]}$ In addition, it has been shown ${ }^{[4,5]}$ that mechanical properties decline with increasing plate thickness. Thicker plates tend to have more segregations in the center region compared to thinner plates. In a previous study, ${ }^{[6}$ the segregation locations were found to have lower impact toughness and the fracture surfaces of the test samples showed more signs of brittle behavior compared to the surrounding regions.

The manufacturing and processing of thick plates include cutting. The most commonly applied cutting method is flame cutting, which is suitable for thick and hard steel plates and high production rates. The cutting is performed with a heating flame and oxygen jet, which creates continuous chemical reactions between iron and oxygen. Flame cutting creates a heat-affected zone 
(HAZ) at the cut edge of the steel plate which entails microstructural changes and hardness variations. The HAZ consists of three different microstructural regions $^{[7]}$ : a newly formed martensite region, a twophase region, and a tempered region. These three microstructural regions also determine the hardness profile of the cut edge. The hardness is the highest in the newly formed martensite region. The hardness decreases in the two-phase region as the martensite is mixed with the tempered original structure. The lowest hardness occurs just after the two-phase region and then the hardness gradually increases as the tempering of the original structure decreases while going deeper toward the subsurface. ${ }^{[6,7]}$ Both the hardness and the microstructure of the tempered region depend on the original microstructure of the steel plate. ${ }^{[6]}$

In addition to microstructural changes and hardness variations, flame cutting causes high residual stresses in the cut edge of the steel plate. Residual stresses arise from local structural constraints inside the material or component. For example, local plastic deformation or local volume change are equilibrated by elastic strains to ensure dimensional continuity. In flame cutting, residual stresses can be divided into two types: thermal and transformation stresses. Thermal stresses originate from the different heating and cooling rates experienced by the surface and the interior of the steel plate. ${ }^{[8]}$ Transformation stresses arise from different microstructural transformations, which are accompanied by volume changes. ${ }^{[8]}$ Previous studies ${ }^{[6,7,9-11]}$ have shown that flame cutting causes both residual compressive stress and high-tensile stress in the cut edge of the steel plate. The compressive stress is produced in the martensite region close to the cut edge and it is followed by high-tensile stress region in the tempered region. ${ }^{[7]}$ The magnitude of the stresses and the width of these regions can be affected by the flame cutting parameters, ${ }^{[9,10]}$ grain structure, ${ }^{[7]}$ and the thickness of the plate. ${ }^{[6]}$

In the worst case, flame cutting causes cracking of the cut edge. Cracks have been observed ${ }^{[7]}$ to form close to the centerline of the plates. Generally, the cracks are a few millimeters in length but on rare occasions they can also propagate catastrophically through the whole plate. The smaller cracks are mostly formed just beneath the cut surface and are usually detected by ultrasonic inspection. Crack formation is exacerbated by residual tensile stresses while compressive stresses have the reverse effect. The microstructural features involved in residual stress formation and cracking behavior were evaluated by the current author in a previous study ${ }^{[7]} \mathrm{It}$ was shown that an elongated prior austenite grain structure is more susceptible to cracking than an equiaxed prior austenite grain structure. The reason for this is that the elongated grain structure creates long, parallel prior austenite grain boundaries that can act as potential crack paths. In addition, the tendency for cracking increases as the plate thickness increases due to the higher number of segregations in thicker plates. ${ }^{[6]}$ In addition, cracking of martensitic steels is often related to temper martensite embrittlement (TME) or temper embrittlement (TE). ${ }^{[12-14]}$ TME occurs in tempering at around $300{ }^{\circ} \mathrm{C}$ and is associated mainly with the formation of cementite at the interlath boundaries of the martensite or at the prior austenite grain boundaries. TE occurs after tempering or cooling through a temperature range of around $500{ }^{\circ} \mathrm{C}$ and is associated mostly with segregation of impurities, such as antimony, phosphorus, tin, and arsenic into the prior austenite grain boundaries. Many studies ${ }^{[15-19]}$ have concentrated on phosphorus, as it can be very detrimental for steel, even in trace amounts. However, the segregation of phosphorus and the cohesion of grain boundaries are also heavily affected by alloying elements. ${ }^{[20]}$ The interaction of impurity and alloying elements has an effect on their segregation into the grain boundaries and eventually on the grain boundary cohesion. For example, nickel, manganese, and chromium strongly co-segregate with phosphorus and increase the risk of TE. In contrast, molybdenum also has a strong interaction with phosphorus and has a beneficial effect on TE by preventing phosphorus segregation and increasing the grain boundary cohesion. ${ }^{[2,20]}$ In addition, hydrogen is typically very harmful for these kind of applications and the hydrogen embrittlement is a widely studied topic. ${ }^{[21-24]}$ However, hydrogen embrittlement also requires susceptible microstructure and stress state which are the mainly focused in this study.

Although flame cutting generates high-residual tensile stresses, they are not high enough alone to break the thick wear-resistant steel plate in normal conditions (without flame cutting). For this reason, there are unknown microstructural factors that contribute to crack formation in flame cutting besides residual stress. The objective of this study was to identify the main factors behind the crack formation in flame cut heavy steel plates. To achieve this, flame cut plate samples containing cracks were studied by electron microscopy and mechanical testing. The findings of this study aim to reduce cracking, and therefore, improve the flame cutting of thick plates in the steel industry and among end users. In addition, the results will significantly increase the effectiveness and productivity of the flame cut process.

\section{EXPERIMENTAL PROCEDURE}

The investigated samples were industrial continuously cast and hot-rolled, wear-resistant steel plates with thicknesses of 40 and $60-\mathrm{mm}$. The plates were manufactured using two different hot-rolling practices: at higher rolling finish temperature (condition A, above $900{ }^{\circ} \mathrm{C}$ ) and lower rolling finish temperature (condition $\mathrm{B}$, below $900{ }^{\circ} \mathrm{C}$ ). One side of the samples was flame cut with an oxyfuel propane gas flame (sample dimensions: thickness 40 or $60-\mathrm{mm}$, width $150 \mathrm{~mm}$, and length 150 $\mathrm{mm})$. Figure 1 illustrates the flame cut sample with the dimensions and test locations. After flame cutting, the samples were ultrasonically inspected with a Phasor XS 16/16 Olympus with a MSEB 4 dual probe $(4 \mathrm{MHz})$ to reveal cracks from the cut edge. The above-described samples that contained cracks were further studied, and therefore, were the main focus of this study. Table I presents the nominal composition (analyzed by optical 


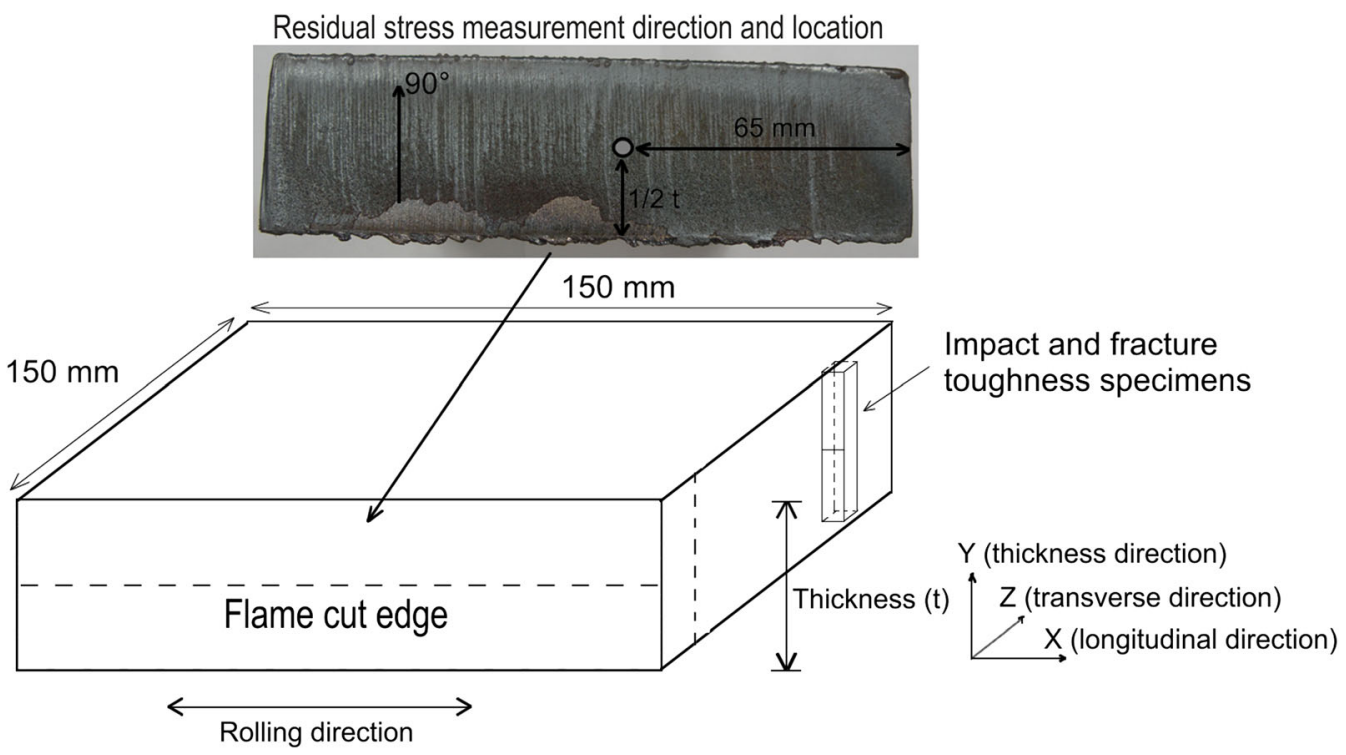

Fig. 1-Flame cut sample with dimensions, flame cut edge and the test locations.

Table I. Chemical Composition of the Studied Steels

\begin{tabular}{lcccccccc}
\hline & \multicolumn{9}{c}{ Weight Percent } \\
\hline & Thickness $(\mathrm{mm})$ & $\mathrm{C}$ & $\mathrm{Si}$ & $\mathrm{P}$ & $\mathrm{V}$ & $\mathrm{Cr}$ & $\mathrm{Mn}$ & $\mathrm{Mo}$ \\
\hline Steel A & 40 & 0.15 & 0.62 & 0.01 & 0.04 & 0.62 & 1.10 \\
Steel B & 40 & 0.14 & 0.55 & 0.01 & 0.04 & 0.57 & 1.05 & 0.42 \\
Steel A & 60 & 0.16 & 0.61 & 0.01 & 0.04 & 0.60 & 1.09 & 0.40 \\
Steel B & 60 & 0.14 & 0.60 & 0.01 & 0.04 & 0.61 & 1.07 & 0.40 \\
\hline
\end{tabular}

emission spectrometry (OES)) and thickness of the studied samples.

After ultrasonic inspection, the studied samples were sectioned and prepared for scanning electron microscopes (SEMs) and for hardness measurements. The sectioned samples were ground with abrasive $\mathrm{SiC}$ papers and polished with 3 - and $1-\mu \mathrm{m}$ diamond suspensions. After polishing, the samples were etched with 4-pct Nital solution. Microstructural characterization was performed with a Zeiss ULTRAplus field emission SEM (FE-SEM), which was equipped with an X-MaxN 80 (Oxford Instruments) Energy-Dispersive X-ray Spectrometer (EDS). The sectioned samples were also utilized in hardness profiling (HV $0.2 \mathrm{~kg}$ ), which was done using a Matsuzawa MMT-X7 digital microhardness tester. In addition, the hardness profile (HV $5 \mathrm{~kg}$ ) in the thickness direction was performed with a Struers DuraScan 80.

The studied $60-\mathrm{mm}$ steel plates were tested with Charpy V-notch impact tests and fracture toughness tests. The impact tests were performed according to EN-ISO 148-1 standard ${ }^{[25]}$ and the samples were sectioned into square bars in the thickness direction with dimensions of $10 \mathrm{~mm} \times 10 \mathrm{~mm} \times 55 \mathrm{~mm}$. That is, the anticipated fracture plane coincided with the center plane of the steel plate. It should be noted that this orientation of Charpy specimens could be achieved only for $60-\mathrm{mm}$, the plate thickness was insufficient in case of thinner plates (for specimen length of $55 \mathrm{~mm}$ ). The test temperatures were $-10,0,22$, and $60{ }^{\circ} \mathrm{C}$ and the presented results are an average of at least three repetitions. The tests were performed on samples with an as-rolled initial microstructure and with a heattreated structure. Heat treatments were designed to simulate the conditions of the tempered region of flame cut samples and were performed in a furnace under normal atmosphere. In heat treating, the samples were held for 70 minutes in the furnace at a temperature of $300{ }^{\circ} \mathrm{C}$ (marked ht300) and cooled to room temperature freely in air. In addition to impact tests, the steel samples were tested for fracture toughness in the thickness direction according to the ASTM E1820 standard. ${ }^{[26]}$ Fracture tests were performed at temperatures of -40 , $-20,0$, and $22^{\circ} \mathrm{C}$ and the presented results are an average of three tests. The tests were done on the samples with the initial microstructures and with the heat-treated structures. The fracture toughness test samples were held for 70 minutes in the furnace at temperatures of 300 and $600{ }^{\circ} \mathrm{C}$ (marked ht300 and ht600, respectively). These temperatures were chosen as they often cause tempered martensite embrittlement $\left(300^{\circ} \mathrm{C}\right)$ and temper embrittlement $\left(600^{\circ} \mathrm{C}\right)$. 
In addition, the residual stress states were measured from some of the cracked samples. The residual stress measurements were performed with an XStress 3000 X-ray diffractometer and the measurement method used was the modified Chi method. ${ }^{[27]}$ The residual stress measurement procedure has been described more precisely in previous studies. ${ }^{[7,9,10]}$ The residual stress measurements were done in both the flame cut direction (0 deg) and the thickness direction (90 deg). However, the residual stresses in the thickness direction are the most important and are focused on in this study as cracks are generally formed in the horizontal direction.

\section{RESULTS}

The focus of this research is on 40- and 60-mm-thick plates that were cracked in flame cutting. These plates were manufactured using previously described hot-rolling practices $\mathrm{A}$ and $\mathrm{B}$. The main difference between these two rolling practices is that $\mathrm{A}$ produced equiaxed prior austenite grains and B horizontally elongated prior austenite grains. ${ }^{[7]}$ In addition, it is generally known that the cooling conditions of thick plates are not homogenous in the thickness direction, thus resulting in different microstructures at different depths. For the $40-\mathrm{mm}$ plates, both rolling practices produced microstructures containing a mixture of bainite and martensite in the center region and mostly martensite at the $1 / 4$ thickness of the plate. However, for the $60-\mathrm{mm}$ plates, the microstructure was mostly bainite in the center region and a mixture of bainite and martensite at the $1 / 4$ thickness. Figure 2 presents the microstructures from $1 / 2$ and $1 / 4$ depths of the $40-$ and $60-\mathrm{mm}$ plates.

Figure 3 shows an example of a typical crack formed in centerline of the 40-mm-thick plate (steel B) and the residual stress state measured from a non-cracked location. In addition, Figure 3 shows the typical microstructural regions formed during flame cutting: newly formed martensite (1), two-phase region (2), and tempered region (3). The crack is located in the tempered region (3) where the highest residual tensile stress values are also found $(\sim 600 \mathrm{MPa})$.

Figure 4 shows the hardness profiles and measurements around the crack and the cut edge. The hardness profiles ( 1 to 5 ) from the cut edge toward the base material show the typical hardness variations occurring due to microstructural changes caused by flame cutting. However, the profiles closer to the crack (1 and 2) show higher hardness in the tempered region $(1.5$ to $3 \mathrm{~mm})$ than the other profiles (3 to 5).

Segregations are known to produce locally harder regions in the structure. ${ }^{[6,28]}$ Segregations here consist of a fully martensitic structure and areas surrounding the segregations have a mostly bainitic structure. In addition, segregations may contain inclusions and precipitates. Figure 5 presents examples of the segregations, inclusions, and precipitates found in the studied steels. The segregations, inclusions, crack location, precipitates, and the segregation surroundings were studied by EDS. Figure 6 shows the EDS line scan results from the segregation and it can be seen that the amount of Mo, $\mathrm{Cr}, \mathrm{Si}, \mathrm{Mn}$ is at least doubled in the segregation region compared to the surrounding structure. In addition, the EDS measurements showed that the segregations contained also elevated amounts of $\mathrm{V}$ and $\mathrm{P}$. The inclusions contained even higher amounts of Mo and P compared to the segregations. The precipitates were rich in $\mathrm{Ti}$ and $\mathrm{N}$, which indicates that the precipitates were titanium nitrides. Figure 7 compares the wt pet of $\mathrm{Si}, \mathrm{P}, \mathrm{V}, \mathrm{Cr}$, $\mathrm{Mn}$, and Mo in the inclusions, segregations, close to the crack, and in the surroundings for the 40-mm-thick steel B. The bars show the average value for each element and the error bar shows the highest and lowest value of the measurements. The EDS results from the matrix was similar to the nominal composition (OES). In addition, the EDS results from these structural details were similar between different thicknesses and steel types. However, steel A contained somewhat fewer segregations compared to steel B.

To evaluate the differences between the as-rolled original structure and the tempered structure (heattreated), a series of Charpy $\mathrm{V}$-notch impact tests were performed on the 60 -mm-thick plate. Figure 8 shows the difference of the impact test results between the original samples (A and B) and the heat-treated samples (ht300). The results show that the heat-treated samples have significantly lower impact energy compared to the original samples. In the tested temperature range, the impact toughness values drop 40 to 60 percent in both steel types (A and B) with the heat-treated samples (ht300) when compared to the original steel structure. In addition, the difference in the impact results is higher as the test temperature increases. The results between different rolling practices are still almost the same. In addition, fracture toughness tests were performed on the 60-mm-thick samples to further evaluate the mechanical properties of the original structure and the tempered regions. Testing was carried out on both the samples in original condition (A and B) and the heat-treated samples (ht300, ht600). Similarly, to the impact test results, the fracture toughness of the tempered region is also lower compared to the original structure, as can be seen in Figure 8. In the tested temperature range, the fracture toughness values drop 15 to 40 pct in both steel types (A and B) with heat-treated samples (ht300 and ht600) when compared to the original steel structure.

To evaluate the results further, the fracture surfaces were examined by SEM and Figures 9(a) and (b) shows the two types of fracture surfaces that were found in the impact and fracture toughness test samples made from $60-\mathrm{mm}$ plate. Most of the samples (original and ht300 in both impact and fracture toughness tests) contained transgranular (Figure 9(a)) fracture surfaces. However, the ht600 fracture toughness samples contained an intergranular fracture surface (Figure 9(b)), which is typical of a weakened grain boundary structure. In addition, several of the studied cracks were opened and investigated by SEM. Figure 9(c) shows an example micrograph of the opened crack surface. It clearly shows that the fracture surface exhibits intergranular cracking behavior and that there are no traces of transgranular cracking behavior. 

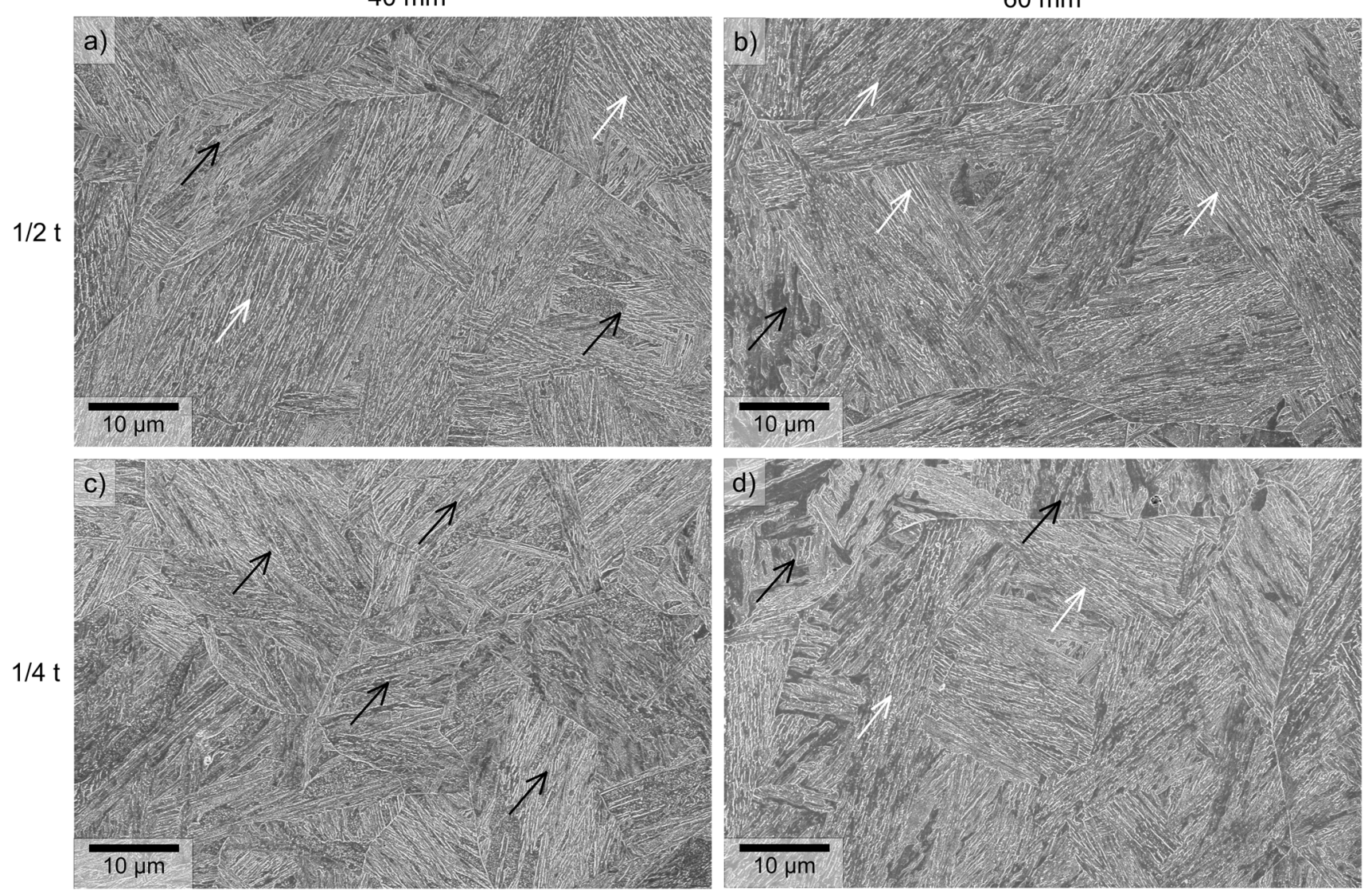

Fig. 2-SEM micrographs from 40- and 60-mm-thick plates. (a) $1 / 2$ thickness, mixture of bainite and martensite and $(c) 1 / 4$ thickness, mostly martensitic microstructures of the $40-\mathrm{mm}$ plate and $(b) 1 / 2$ thickness, mostly bainite and $(d) 1 / 4$ thickness, mixture of bainite and martensite microstructures of the $60-\mathrm{mm}$ plate. Examples of martensite and bainite are marked in the micrographs with black and white arrows, respectively.

\section{DISCUSSION}

Micrographs of the original structures of the studied steels show similar results to those of a previous study. ${ }^{[6]}$ The amount of martensite in the structure decreases and the bainite structure increases toward the center of the plate. In the $40-\mathrm{mm}$ plates, the microstructure is mostly martensite at $1 / 4$ thickness and a mixture of martensite and bainite at $1 / 2$ thickness. In the $60-\mathrm{mm}$ plates, the microstructure is a mixture of martensite and bainite at $1 / 4$ thickness and mostly bainite at $1 / 2$ thickness. These microstructures are formed due to the different cooling conditions as the plate thickness increases.

Cracking of the martensitic steels is widely studied topic ${ }^{[29-33]}$. However, the present study concentrates on the more limitedly reported cracking behavior of steel plate structure under the heating and residual stress state caused by flame cutting. The examination of the cracked $40-\mathrm{mm}$ plate shows the specific location of the crack in the flame cut edge. The crack is formed in the centerline of the plate and in tempered region, where flame cutting also causes the highest residual tensile stresses. In addition, it is formed in the locally harder region, which suggests that the crack is located in the segregation. Micrographs of the segregations show that they are formed horizontally as strings or sheets between the surrounding structure near the center region of the plates. The microstructure of segregations is fully martensitic, whereas the surrounding structure is mostly bainite or a mixture of bainite and martensite. The reason for this is that the segregations contain elevated amounts of alloying elements, which increase the hardness and hardenability. In addition, the composition of the segregations affect local tempering behavior during flame cutting. For example, Si, V, Cr, and Mo are known to stabilize the tetragonality of martensite during tempering and $\mathrm{Si}, \mathrm{Cr}$, and $\mathrm{Mo}$ also hinder the formation and coarsening of cementite, which is the main factor responsible for tempered martensite embrittlement (TME). ${ }^{[12]}$ In addition, it has been stated ${ }^{[1,3]}$ that segregations typically have a higher concentration of $\mathrm{C}$, which can further increase hardness and hardenability. However, the amount of $\mathrm{C}$ is difficult to evaluate with EDS, so this can only be speculation. For these reasons, the segregations effectively maintain their hardness (and brittleness) during tempering while the surrounding structure becomes softer and more ductile. Similar behavior has been reported earlier ${ }^{[28]}$ where segregation transforms to hard phase which would not withstand further manufacturing conditions (for example forging). It was also noticed that crack location had higher concentrations of $\mathrm{C}, \mathrm{Cr}, \mathrm{Mo}, \mathrm{P}$, and $\mathrm{S}$ due to the 


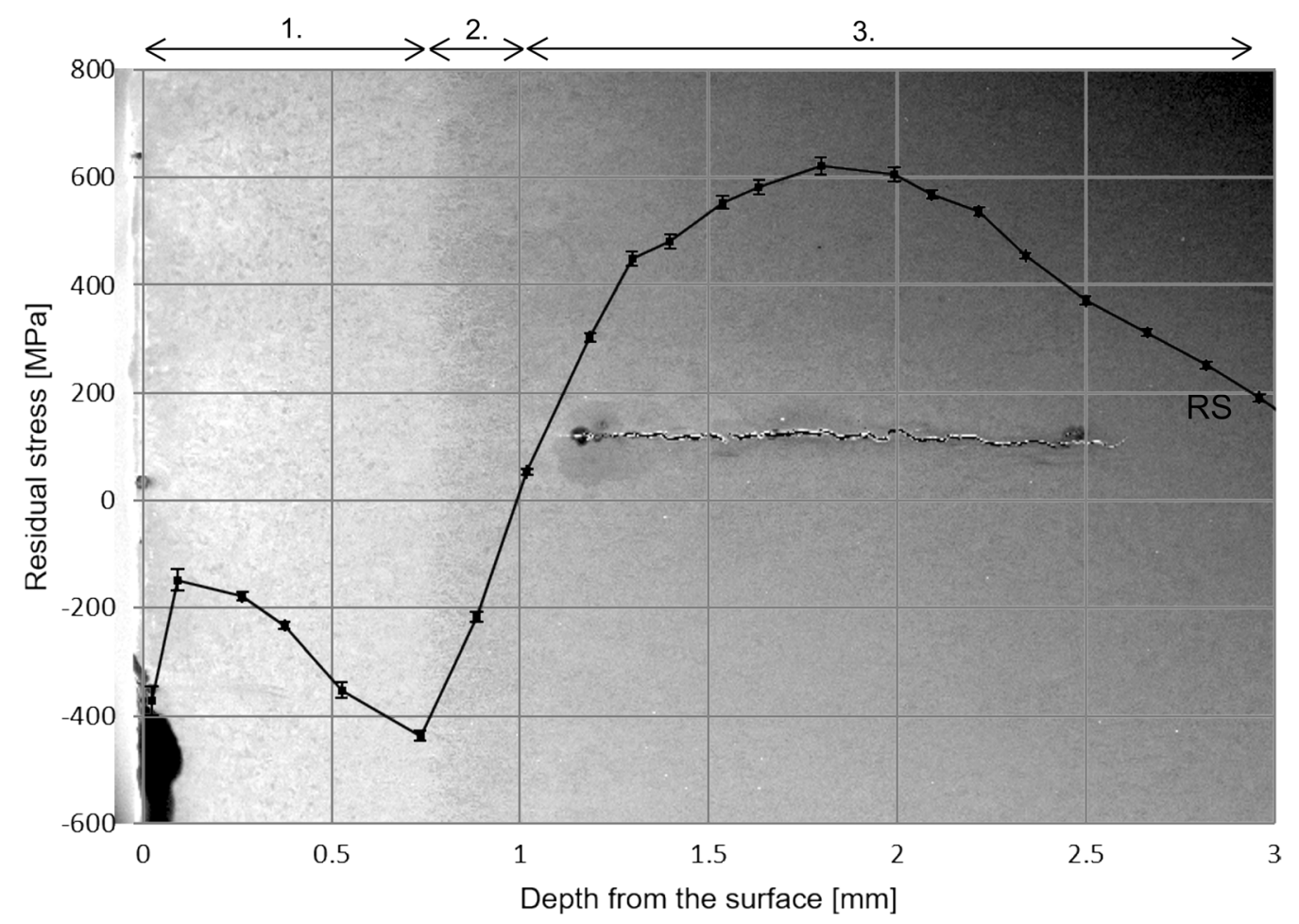

Fig. 3-Residual stress (RS) state and crack location in the flame cut edge of 40-mm plate (steel B). Microstructural regions formed during flame cutting: newly formed martensite (1), two-phase region (2), and tempered region (3).
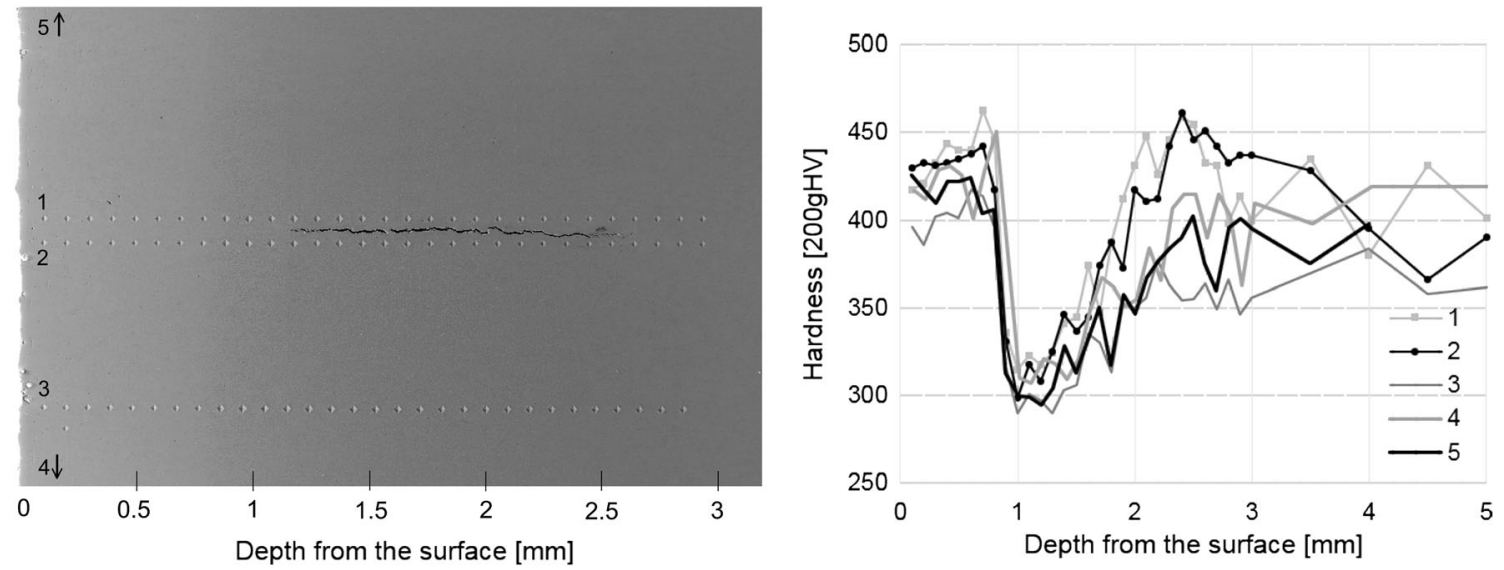

Fig. 4-Hardness measurements from the cut edge of the cracked 40-mm plate (steel B).

segregation. ${ }^{[28]}$ In the present study, segregations also contain inclusions, and titanium nitride precipitates which can create harmful discontinuities and stress concentrations to the steel structure.

The impact and fracture toughness tests show that tempering during flame cutting weakens the structure of the cut edge. The test results of the heat-treated samples have clearly lower impact (40 to $60 \mathrm{pct}$ ) and fracture toughness (15 to $40 \mathrm{pct})$ properties compared to the original samples. However, the interesting point was that the fracture mechanisms differed between the heat-treated samples. The original samples and $300{ }^{\circ} \mathrm{C}$ heat-treated samples contained transgranular fracture surfaces. The lower impact and fracture toughness of the
$300{ }^{\circ} \mathrm{C}$ heat-treated samples indicates the formation of brittle cementite in the interlath sites of the martensite (typical of TME). However, samples heat-treated at 600 ${ }^{\circ} \mathrm{C}$ contained intergranular fractures similar to those in the cracks caused by flame cutting. This indicates that samples heat-treated at $600{ }^{\circ} \mathrm{C}$ and flame cut cracks are formed by the same mechanism. The results suggest that the primary reason for cracking is the decohesion of the prior austenite grain boundaries and the main reason for this is the accumulation of impurity and alloying elements on the grain boundaries. Therefore, in the present study, tempering decreased the cohesion of the grain boundaries and lowered ductility and fracture toughness. 

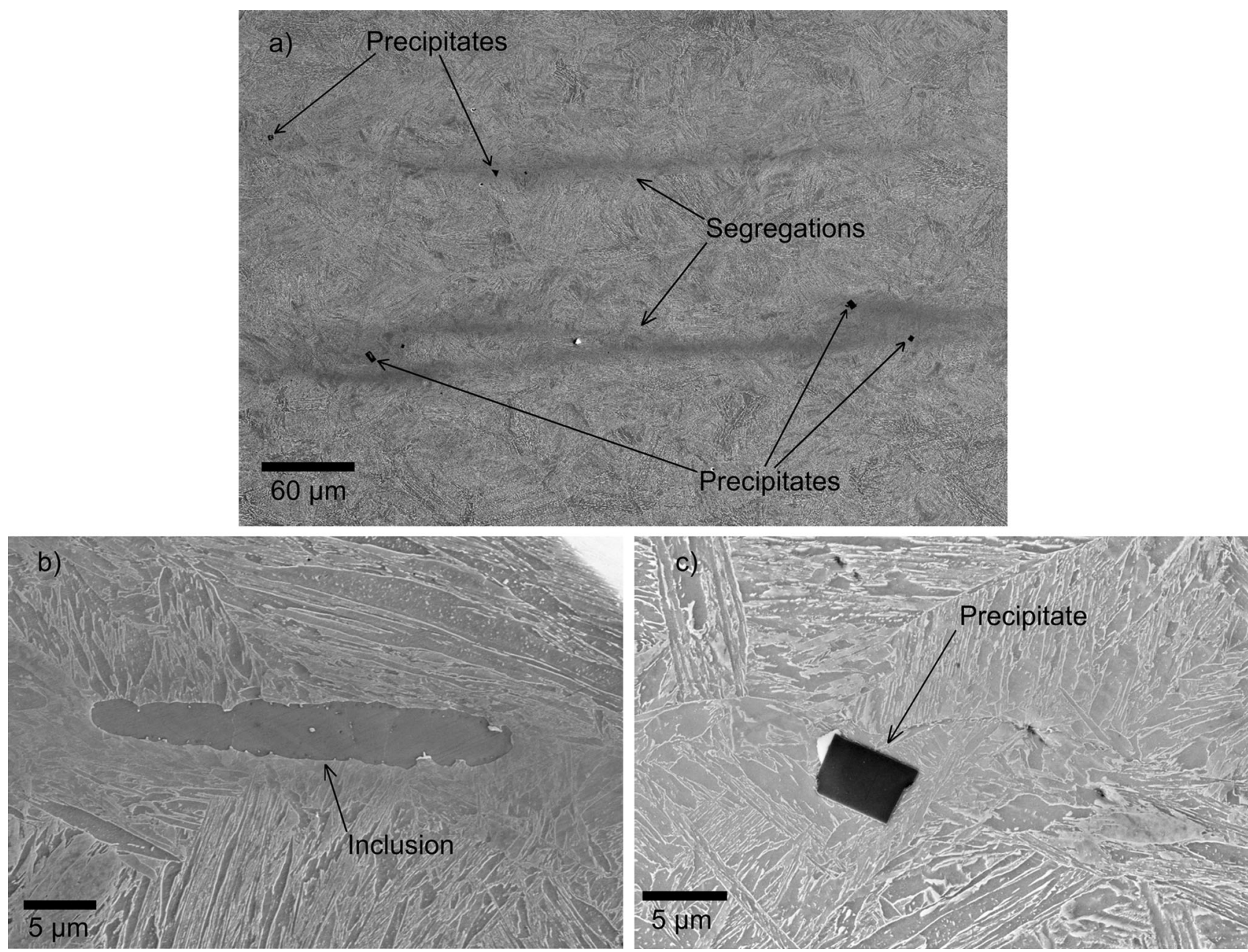

Fig. 5-Micrographs of the (a) segregations and precipitates, $(b)$ inclusion, and (c) precipitate.
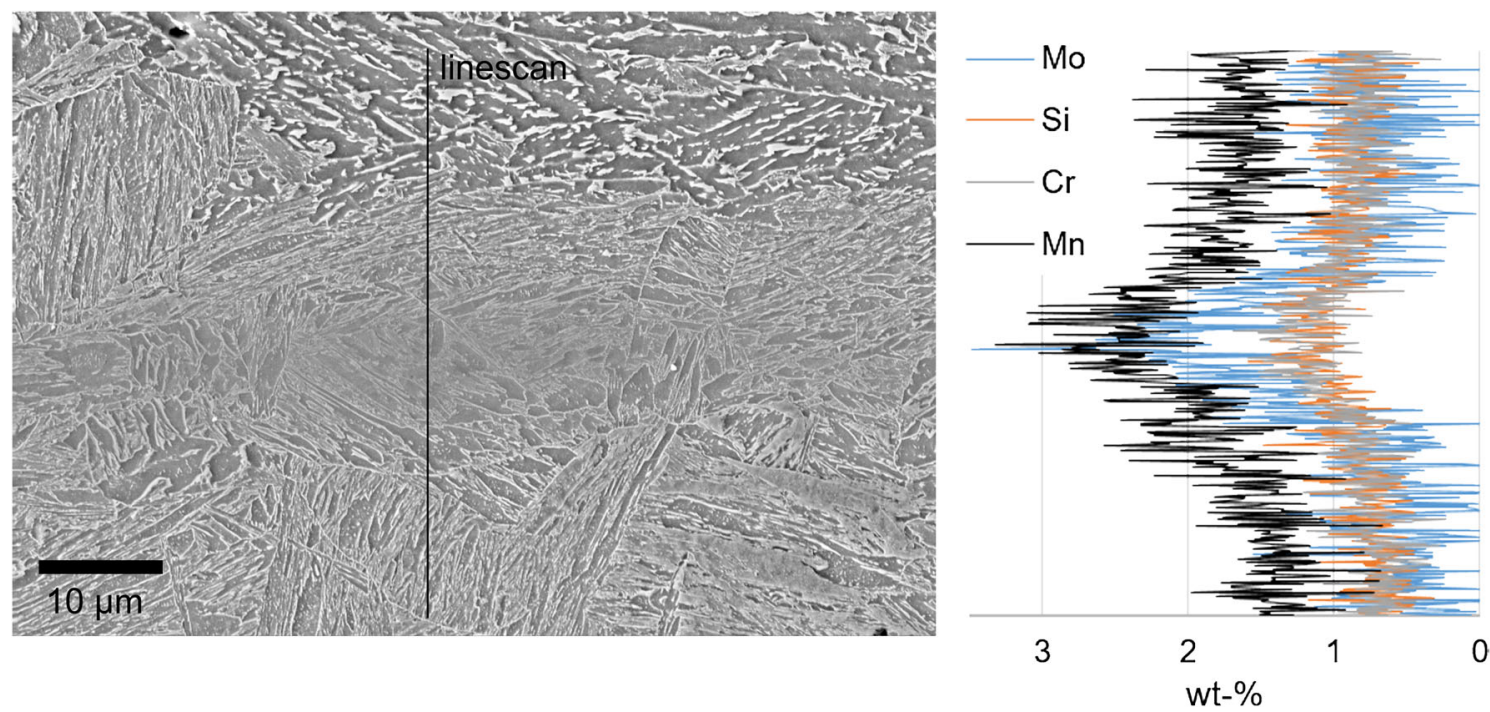

Fig. 6-EDS line scan of the segregation. (For interpretation of the colors in these figures, the reader is referred to the web version of this article.). 


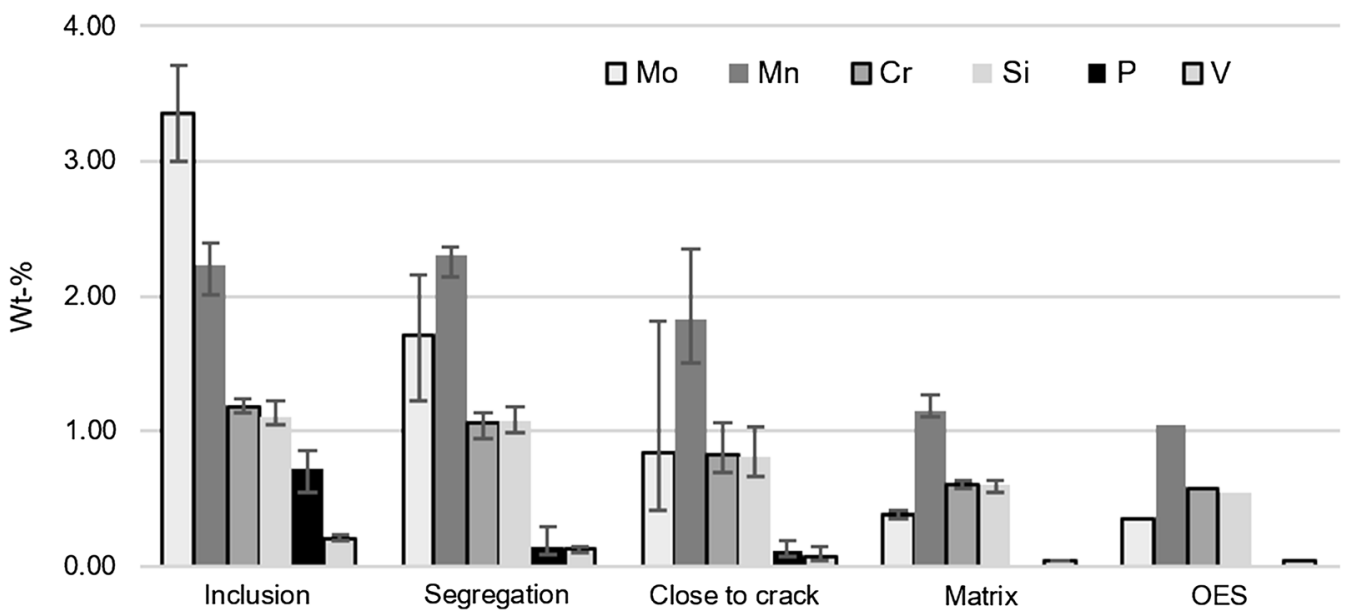

Fig. 7-Comparison of $\mathrm{Si}, \mathrm{P}, \mathrm{V}, \mathrm{Cr}, \mathrm{Mn}$, and Mo contents between inclusion, segregation, close to crack, matrix, and nominal composition (OES).

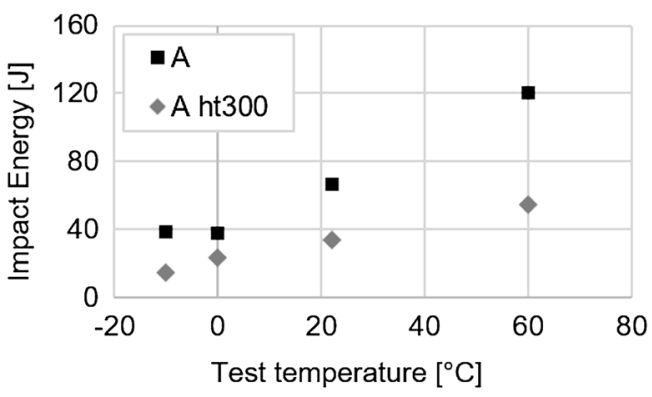

(a)

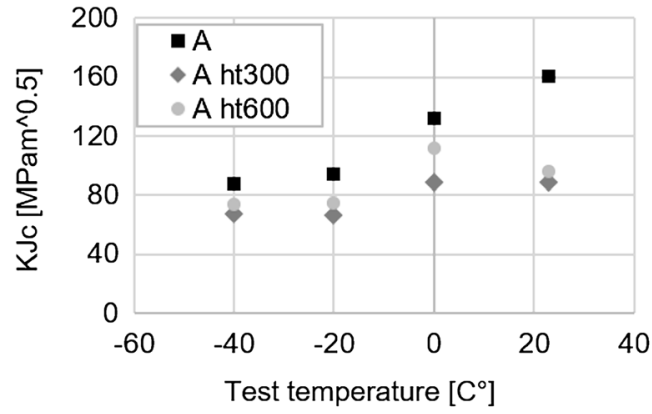

(c)

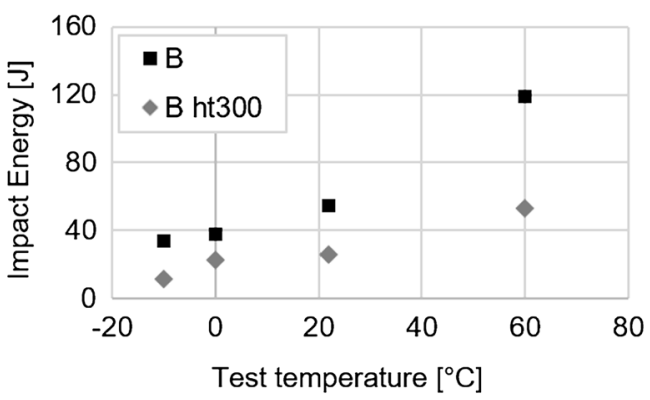

(b)

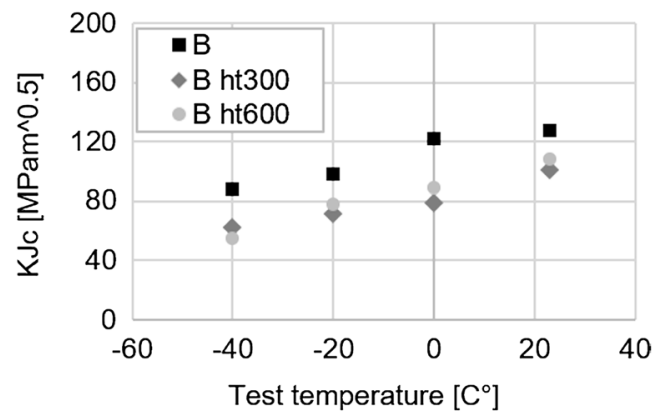

(d)

Fig. 8 - Charpy-V impact test results of samples $(a)$ A and (b) B (original and heat-treated specimens (ht300)) and fracture toughness test results of samples $(c)$ A and $(d)$ B (original and heat-treated specimens (ht300 and ht600)) from 60-mm plates.

Cracks are formed in the locally harder segregations, which contain significantly higher amounts of $\mathrm{Si}, \mathrm{P}, \mathrm{V}$, $\mathrm{Cr}, \mathrm{Mn}$, and Mo compared to the surrounding regions or the nominal composition of the steels. The fracture path follows the prior austenite grain boundaries, which indicates a reduced cohesion of prior austenite grain boundaries. P can be classified as an impurity element and it decreases the grain boundary cohesion, which is one of the main factors causing temper embrittlement (TE) in steels. ${ }^{[12,20]}$ However, the other alloying elements found in the segregation also interact with $\mathrm{P}$ and each other, which affects both the segregation of these elements on the grain boundaries and the grain boundary cohesion. For example, the interaction of $\mathrm{P}$ and $\mathrm{Mn}, \mathrm{Cr}$, and $\mathrm{Mo}$ is attractive and they enhance the segregation of the others. Therefore, not only has the segregation of $\mathrm{P}$ to be considered but also the segregation of the other alloying elements and their effect on grain boundary decohesion. $\mathrm{Mn}$ and $\mathrm{Cr}$ strongly co-segregate with $\mathrm{P}$, increasing the risk of TE, and $\mathrm{Mn}$ enhances the embrittling potency of $\mathrm{P} .{ }^{[20]}$ In addition, it has been mentioned ${ }^{[12]}$ that $\mathrm{Si}$ increases TE, although it shows repulsive interaction with both $\mathrm{C}$ and $\mathrm{P} \cdot{ }^{[20]} \mathrm{In}$ contrast, TE susceptibility is partially decreased by adding Mo up to $0.7 \mathrm{wt}$ pct as it inhibits the segregation of $\mathrm{P}$ and enhances grain boundary cohesion. However, 

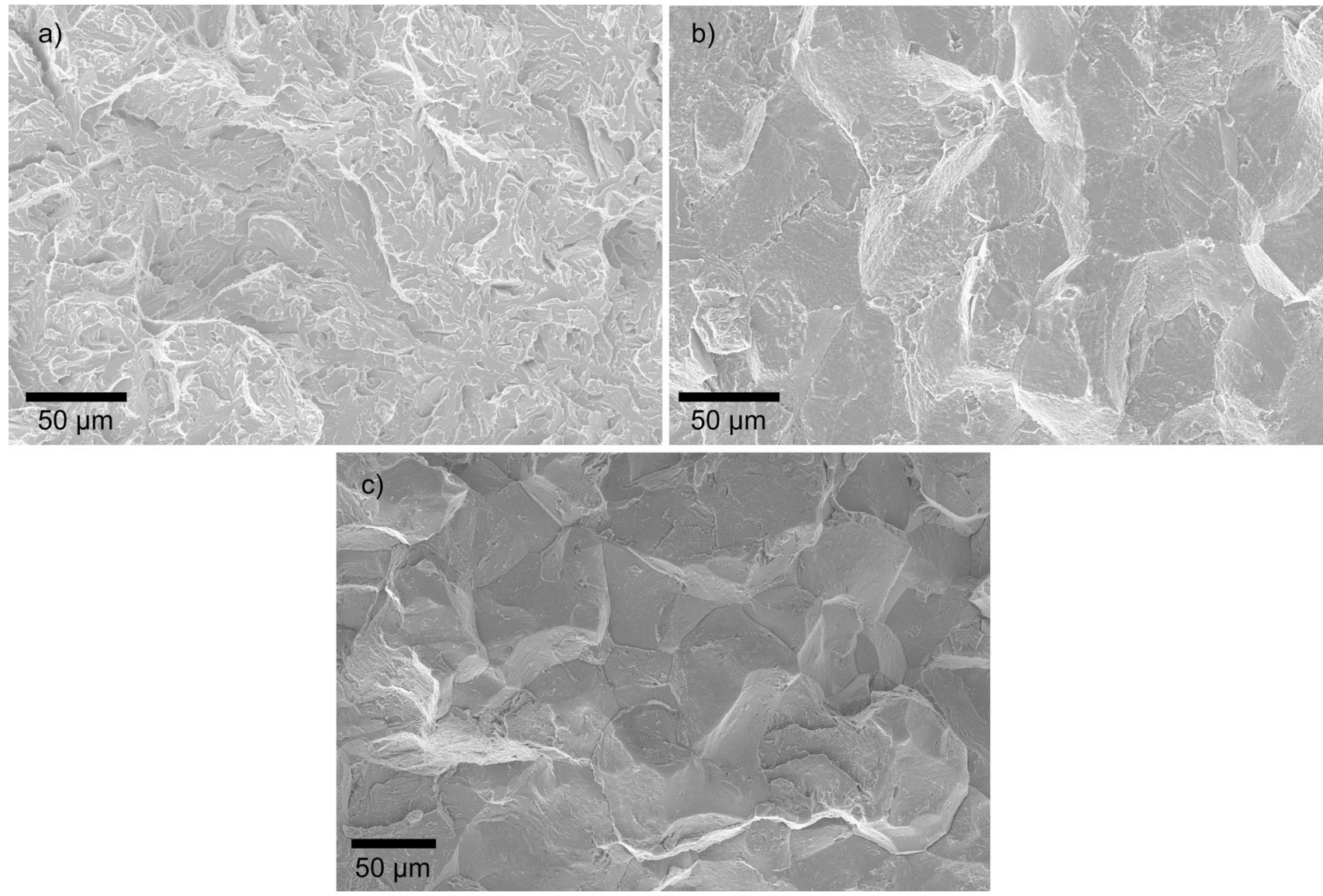

Fig. 9-Fracture surfaces of fracture toughness test samples, made from 60-mm plates, showing $(a)$ transgranular fracture, $(b)$ intergranular fracture, and $(c)$ opened flame cut crack fracture surface from 60 -mm-thick flame cut sample.

larger additions of Mo are inefficient as it is then incorporated in cementite. ${ }^{[20]}$ On the other hand, interaction between $\mathrm{P}$ and $\mathrm{C}$ is competitive for iron and additions of $\mathrm{C}$ generally depress $\mathrm{P}$ segregation. However, strong carbide-forming elements such as $\mathrm{Cr}$, Mo, V lower the $\mathrm{C}$ solubility and therefore promote the embrittling segregation of $\mathrm{P}$ by depressing segregation of $C^{[8,12,20]}$ As it turns out, the elements in the segregation have a very complex interaction with each other and the combination of these elements significantly affects the cohesion of the prior austenite grain boundaries. Most of the elements have undesired effects although some may also have a beneficial effect. However, if a crack is formed, it is safe to say that the combined effect of these elements leads to unwanted results. In addition, as previously has been studied ${ }^{[21-24]}$ hydrogen can be detrimental for this kind of applications. It should be noted that based on this study the effect of hydrogen cannot be totally ruled out. However, if the hydrogen is involved, it can only enhance cracking behavior of already susceptible microstructure and existing stress state.

So what are the main causes behind crack formation in the flame cutting of thick wear-resistant steel plates? Previous studies ${ }^{[6,7,9,10]}$ have clearly shown that incorrect cutting practices produce high residual tensile stresses in the cut edge. The results of the current study show that impact and fracture toughness is reduced by heat treatment that resembles the conditions of the tempered region. In particular, the samples that were heat treated at $600{ }^{\circ} \mathrm{C}$ had intergranular fracture surfaces similar to the cracks formed in flame cutting. Generally, this temperature range promotes the segregation of impurity and alloying atoms on the grain boundaries and reduces the cohesion of the boundaries. In addition, the results showed that segregations contained increased amounts of alloying elements compared to the surroundings. These elements have a variety of effects and they interact with each other in many ways. However, in crack formation, the combined effect of these elements reduces the prior austenite grain boundary cohesion in such a harmful manner that the grain boundaries cannot withstand the high residual tensile stresses produced by flame cutting.

To avoid crack formation, the manufacturing process of thick wear-resistant steel plates should aim to minimize the amount of segregation and reduce the amount of harmful impurity and alloying elements. The manufacturing of the plates should also favor microstructures that are not too prone to the critical temperature around $600{ }^{\circ} \mathrm{C}$ which decreases grain boundary cohesion and lowers the fracture toughness of the plates. In addition, flame cutting of thick plates should favor parameters that produce low residual 
stresses in the cut edge. These results and guidelines will improve the effectiveness of flame cutting and lower the cracking probability of thick wear-resistant steel plate during the flame-cutting process.

\section{CONCLUSIONS}

On the basis of this research, the following conclusions can be summarized:

1. Cracks form in locally harder segregations in the plate centerline together with tempered region where the highest residual tensile stress is also formed due to flame cutting.

2. Segregations are enriched by alloying elements such as $\mathrm{Si}, \mathrm{P}, \mathrm{V}, \mathrm{Cr}, \mathrm{Mn}$, and Mo, and therefore, exhibit higher hardness and stronger hardenability compared to the surroundings. During the flame-cutting process, this increased content of impurity and alloying elements reduces the cohesion of the prior austenite grain boundaries, which then fail to withstand the residual tensile stresses generated during flame cutting.

3. The samples simulating tempered region of the HAZ has 40 to 60 pet lower impact and 15 to 40 pet fracture toughness than the as-rolled original structure. Temperature ranges around $300{ }^{\circ} \mathrm{C}$ and around $600{ }^{\circ} \mathrm{C}$ lower the ductility and fracture resistance of the plate. The samples heat-treated at $600{ }^{\circ} \mathrm{C}$ and flame cut cracks both exhibited intergranular crack surfaces.

4. To avoid cracking, steel plates should not contain severe segregations and manufacturing should aim to steel microstructure that preserves its grain boundary cohesion and fracture toughness during flame cutting. In addition, high-residual tensile stresses should be avoided by cutting parameters optimization.

\section{ACKNOWLEDGMENTS}

The research was mainly funded by the Tampere University of Technology graduate school. This work made use of Tampere Microscopy Center facilities at Tampere University. The authors would like to express their gratitude to Mr. Turo Salomaa for his considerable help with mechanical testing.

\section{OPEN ACCESS}

This article is licensed under a Creative Commons Attribution 4.0 International License, which permits use, sharing, adaptation, distribution and reproduction in any medium or format, as long as you give appropriate credit to the original author(s) and the source, provide a link to the Creative Commons licence, and indicate if changes were made. The images or other third party material in this article are included in the article's Creative Commons licence, unless indicated otherwise in a credit line to the material. If material is not included in the article's Creative Commons licence and your intended use is not permitted by statutory regulation or exceeds the permitted use, you will need to obtain permission directly from the copyright holder. To view a copy of this licence, visit http://creat ivecommons.org/licenses/by/4.0/.

\section{REFERENCES}

1. S.K. Choudhary, S. Ganguly, A. Sengupta, and V. Sharma: $J$. Mater. Process. Technol., 2017, vol. 243, pp. 312-21.

2. N. Yang, C. Su, X. Wang, and F. Bai: J. Constr. Steel Res., 2016, vol. 122, pp. 213-25.

3. T. Pikkarainen, V. Vuorenmaa, I. Rentola, M. Leinonen, and D. Porter: IOP Conf. Ser., 2016, vol. 117, p. 012064.

4. Y. Wang, X. Liu, Z. Hu, and Y. Shi: Fatigue Fract. Eng. Mater. Struct., 2013, vol. 36, pp. 1258-73.

5. Y. Wang, X. Liao, Y. Zhang, and Y. Shi: J. Zhejiang Univ. Sci. A, 2015 , vol. 16 , pp. $217-28$.

6. T. Jokiaho, S. Santa-aho, P. Peura, and M. Vippola: Metall. Mater. Trans. A, 2019, vol. 50A, pp. 4178-92.

7. T. Jokiaho, S. Santa-Aho, H. Järvinen, M. Honkanen, P. Peura, and M. Vippola: Mater. Perform. Charact., 2018, vol. 7.

8. H. Bhadeshia and R. Honeycombe: Steels: Microstructure and Properties, 4th ed., Butterworth-Heinemann, Oxford, 2017, pp. 217-36.

9. T. Jokiaho, A. Laitinen, S. Santa-aho, M. Isakov, P. Peura, T. Saarinen, A. Lehtovaara, and M. Vippola: Metall. Mater. Trans. B, 2017, vol. 48, pp. 2891-2901.

10. T. Jokiaho, T. Saarinen, S. Santa-Aho, P. Peura, and M. Vippola: Key Eng. Mater., 2016, vol. 674, pp. 103-08.

11. L. Lindgren, A. Carlestam, and M. Jonsson: J. Eng. Mater. Technol., 1993, vol. 115, pp. 440-445.

12. G. Krauss: Steels: processing, structure, and performance. Asm International, 2015

13. G. Krauss: Reference Module in Materials Science and Materials Engineering, Elsevier, 2016, pp. 5193-5197.

14. H. Bhadeshia and R. Honeycombe: Steels: Microstructure and Properties, 4th ed., Butterworth-Heinemann, Oxford, 2017, pp. $303-388$.

15. J.C. Han, J.B. Seol, M. Jafari, J.E. Kim, S.J. Seo, and C.G. Park: Mater. Charact., 2018, vol. 145, pp. 454-460.

16. A. Karani, S. Koley, and M. Shome: Eng. Fail. Anal., 2019, vol. 96, pp. 289-97.

17. K. Wang and H. Si: J. Iron Steel Res. Int., 2014, vol. 21, pp. 1136-39.

18. S.H. Song, Y. Zhao, and H. Si: Mater. Lett., 2015, vol. 140, pp. 20-22.

19. J. Perháčová, D. Grman, M. Svoboda, J. Patscheider, A. Výrostková, and J. Janovec: Mater. Lett., 2001, vol. 47, pp. 44-49.

20. T. Xu: Reference Module in Materials Science and Materials Engineering, Elsevier, 2016, pp. 1-8.

21. Y. Momotani, A. Shibata, D. Terada, and N. Tsuji: Int. J. Hydrog. Energy, 2017, vol. 42, pp. 3371-79.

22. A. Nagao, C.D. Smith, M. Dadfarnia, P. Sofronis, and I.M. Robertson: Acta Mater., 2012, vol. 60, pp. 5182-89.

23. Q. Liu, Q. Zhou, J. Venezuela, M. Zhang, and A. Atrens: Mater. Sci. Eng. A, 2018, vol. 715, pp. 370-78.

24. J. Yang, Y. Song, Y. Lu, J. Gu, and Z. Guo: Mater. Sci. Eng. A, 2018 , vol. 712 , pp. $630-36$

25. SFS-EN ISO 148-1: Mechanical Engineering and Metals Industry Standardization in Finland, 2016.

26. ASTM E1820 - 17a: Standard Test Method for Measurement of Fracture Toughness, 2017. 
27. EN 15305: Non-destructive Testing Method for Residual Stress analysis by $X$-ray Diffraction, 2008.

28. R. Chu, Z. Li, Y. Fan, J. Liu, C. Ma, and X. Wang: Heliyon, 2019, vol. 5 , p. e01329.

29. C. Wang, M. Wang, J. Shi, W. Hui, and H. Dong: Scripta Mater., 2008, vol. 58, pp. 492-95.

30. T. Zhou, H. Yu, and S. Wang: Mater. Sci. Eng. A, 2016, vol. 658, pp. $150-58$

31. H. Kim, J. Park, M. Kang, and S. Lee: Mater. Sci. Eng. A, 2016, vol. 649 , pp. $57-67$.
32. S. Li, G. Zhu, and Y. Kang: J. Alloys Compd., 2016, vol. 675, pp. 104-15.

33. C. Wang, H. Qiu, Y. Kimura, and T. Inoue: Mater. Sci. Eng. A, 2016, vol. 669, pp. 48-57.

Publisher's Note Springer Nature remains neutral with regard to jurisdictional claims in published maps and institutional affiliations. 